\title{
Os processos de comunicação e mediação da informação no ambiente interno de uma indústria do setor sucroalcooleiro do Estado de São Paulo
}

\author{
Los procesos internos de comunicación y mediación de información de carácter nacional \\ dentro de una industria del sector de azúcar y alcohol en el Estado de São Paulo
}

The internal information communication and mediation processes inside an industry of the sugar and alcohol sector in the State of São Paulo

\author{
Marcio Ferreira da SILVA \\ Universidade Estadual Paulista (UNESP), Marília, São Paulo, Brasil, soimers@marilia.unesp.br
}

\begin{abstract}
Resumen
Se presenta un análisis de los agentes mediadores y el flujo interno de la información en tres departamentos de una industria de alta productividad de etanol en la región de São José do Rio Preto, São Paulo. La investigación se definió como un estudio de caso de muestreo no probabilístico utilizando entrevistas, encuestas y diarios. Los sujetos investigados fueron los encargados, los asistentes administrativos y los técnicos de los departamentos de control de calidad, recursos humanos y seguridad en el trabajo. Como resultado se identificaron los flujos de información, los agentes mediadores y los ruidos que interfieren en los flujos de información interna.
\end{abstract}

Palabras clave: Industria sucroalcoholera. São Paulo (Estado). Comunicación informacional. Mediación informacional. Agentes mediadores de información.

\section{Introdução}

No cenário global amplamente competitivo entre as organizações, a informação é considerada essencial por possibilitar reconhecer o ambiente e lidar com transformações políticas, econômicas, culturais, científicas e tecnológicas. A informação é determinante para as indústrias, em especial, àquelas atuantes em áreas com alta capacidade de inovação. É o caso, por exemplo, das indústrias do setor sucroalcooleiro. O setor da produção de etanol, com base na cana-deaçúcar, possui potencial de causar múltiplos impactos no segmento de energia mundial (Safatle Netto, 2011, p. 15). A preocupação com energia envolve diversas nações do mundo. Agências governamentais, centros e institutos de pesquisa como a Agência de Proteção Ambiental Americana - EPA e União Européia afirmam que não há outro biocombustível em larga escala superior ao etanol de cana-deaçúcar (CNI, 2012, p. 37).

\begin{abstract}
An analysis is presented of the mediators and the internal flow of information in three departments of a high-productivity ethanol industry in the region of São José do Rio Preto, São Paulo. The research project was defined as a case study of non-probability sampling using interviews, surveys and fieldwork diaries. The research subjects were managers, administrative assistants and technicians of the quality control, human resources and occupational safety departments. As a result, the information flows, the mediators and noises disturbing the internal information flows were identified.
\end{abstract}

Keywords: Sugar-alcohol industry. São Paulo (State). Information communication. Information mediation. Information mediation agents.

Mediante a literatura analisada, identificou-se estreita relação entre a história do Brasil e a do setor sucroalcooleiro na composição do parque fabril nacional. Desde a implantação da lavoura canavieira e a constituição do setor sucroalcooleiro no Brasil e no Estado de São Paulo (Petrone, 1968; Pina, 1972; Mont'alegre, 1974; Andrade, 1994; Bray; Ferreira; Ruas, 2000; Galeano, 2001; Furtado, 2005).

Considerando o exposto, entende-se como necessário a realização de pesquisas sobre esta categoria de indústria, fundamental para o desenvolvimento econômico do Brasil. Nesse sentido, a pesquisa buscou analisar os processos internos de comunicação e mediação da informação em uma indústria de alta produtividade no setor sucroalcooleiro do Estado de São Paulo, Brasil. Sob o prisma da Ciência da Informação, analisar a questão da informação em um setor econômico que vem se tornando uma das grandes alternativas em energia renovável, possibilita refletir sobre questões de impacto econômico e social em ambientes de significati- 
vo know-how em atividades que exigem elevada quantidade de informação especializada.

Nesse intuito, torna-se determinante realizar estudos voltados aos processos de comunicação e mediação da informação nos ambientes internos dessas indústrias. Isto representa não só uma necessidade científica, mas também uma preocupação de cunho estratégico ao país e ao estado de São Paulo.

\section{Processos de comunicação e mediação da informação}

A pesquisa buscou desenvolver um quadro conceitual tomando por base reflexões presente em várias áreas do conhecimento como Comunicação, Ciência da Informação, Administração, por exemplo. Estas, por sua vez, contribuíram no construto conceitual da pesquisa. Do latim communis que origina communicare a comunicação significa tornar comum, partilhar, transmissão de mensagens entre pólos (emissor e receptor) com uso de um código e um meio comum a ambas na transferência de informação por diversas linguagens (Furstenau, 1976, p. 233; Rabaça; Barbosa, 2001, p. 107; Sousa, 2004, p. 220-221; Cunha; Cavalcanti, 2008, p. 97). A comunicação é compreendida como um processo complexo, dinâmico e envolvida por inúmeras fases da prática social que, ao mesmo tempo, causa e sofre seus efeitos (Cherry, 1968, p. 22-30; Halliday, 1975, p. 11; Diaz Bordenave, 1985, p. 41).

O ambiente de convívio de pessoas transpõe as dimensões da língua e da fala. Reelaborada diante das necessidades cotidianas por novos aprendizados é comunicado por diferentes possibilidades de canais em espaços de extrema complexidade. Os estudos para compreender o processo de comunicação deram origem a várias abordagens, por exemplo, a Teoria Matemática da Informação, Mass Communication Research, Estudos Culturais (Cultural Studies) e Semiótica (Peirce, 1972; Adorno, 1977; Freitag, 1994; Escosteguy, 2001; Santaella; Noth, 2004; Wolf, 2006; Matellart e Matellart, 2011).

A comunicação no contexto industrial visa aproximar as informações consideradas essenciais ao desempenho das atividades de qualquer indivíduo sobre os processos específicos do ambiente interno. A comunicação da informação é compreendida como um processo que promove a interação ou trocas de informações entre os envolvidos com o processo produtivo composto de cenários de ampla complexidade e multifacetados (Pinho, 2006, p. 28).
A mediação enquanto ação entre dois pólos deriva do termo latino media. Presente em ações de intervenção, aproximação, arbitragem ou intermediação realizada por um terceiro em contextos especializados (Torrinha, 1939, p. 748; Cretella Junior; Cintra 1956, p. 724; Cunha, 2007 , p. 509). No âmbito da comunicação a mediação está envolvida no processo de comunicação em ações de interferência entre seu início e fim (Davallon, 2007; Martin-Barbero, 2009).

As associações ao termo indicam as inúmeras abordagens empregadas com o termo mediação como, por exemplo, mediação de conflito, mediação da leitura, mediação da informação, mediação digital, mediação cultural (Bortolin, 2010, p. 118).

Para Almeida Júnior $(2009$, p. 92) a mediação da informação corresponde em ações que visam proporcionar uma provável apropriação e aproximação da informação.

Trata-se de uma ação de interferência realizada por um agente mediador ou gatekeeper em qualquer espaço de produção e circulação da informação, além dos espaços tradicionais (arquivo, museu e biblioteca). Os agentes são reconhecidos por suas habilidades e conhecimento do ambiente especializado. A mediação da informação está presente na rotina das indústrias reforçada por aspectos valorizados por organizações como a competitividade, inserção internacional, alta produtividade e inovação tecnológica, impacto social e econômico. Contudo, a mediação da informação na indústria retroalimenta o fluxo da informação na indústria entre pessoas e setores internos.

A mediação é toda ação de aproximar a informação de quem dela necessite. Deve ser precisa, registrada ou realizada a partir da experiência do agente mediador de acordo com o segmento da indústria. Conversas entre funcionário de carreira, entrevistas, palestras de integração de novos colaboradores e prestadores de serviço, por exemplo. Exige participação do gatekeeper para resolução de incidentes e à tomada de decisão nos processos produtivos.

\section{Metodologia}

A pesquisa foi classificada como um estudo de caso. Ela teve como intenção aprofundar análise e aproximar-se da realidade abordada (Bruyne; Herman; Scoutheete, 1977, p. 224-227; Yin, 2010, p. 39). A amostragem selecionada foi não-probabilística por tipicidade, em uma indústria de alta produtividade de álcool em 2010 (Ackoff, 1967; Selltiz, 1971; Bruyne, Herman e 
Scoutheete, 1977; Rea e Parker, 2000; Gil, 2009).

Para a coleta dos dados, julgou-se pertinente a escolha de mais de uma técnica, proporcionado maior diversidade de dados para a análise, a saber: entrevista, questionário, diário (Selltiz et. al., 1971; Schleyer, 1982; Sanz-Casado, 1994; Alaszewski, 2006; Fernando, 2010). Para analisar as entrevistas foi utilizado o Discurso do Sujeito Coletivo, uma técnica de análise de depoimentos (Lefèvre e Lefèvre, 2005). Os sujeitos da pesquisa foram encarregados, assistentes administrativos e técnicos dos Departamentos de Controle de Qualidade (CQ), Recursos Humanos (RH) e Segurança no Trabalho (ST). A indústria pesquisada fica localizada na região administrativa de São José do Rio Preto, que em 2010 detinha a maior concentração de unidades industriais em produção de álcool do setor sucroalcooleiro no Estado de São Paulo. No período, a indústria ficou entre as 20 (vinte) maiores em produtividade do ranking de 184 (cento e oitenta e quatro) indústrias elaborado para esta pesquisa.

As entrevistas e diários foram aplicados a 8 (oito) participantes; os questionários foram respondidos por 16 (dezesseis) pessoas entre 17(dezessete) questionários enviados. A pesquisa também preocupou-se com aspectos éticos que preconiza a resolução do Conselho Nacional de Saúde CNS 196/96.

\section{Resultados}

Considerando a reunião dos dados junto aos respectivos departamentos e sua tabulação, de acordo com os dados dos questionários na Tabela I, pode-se notar a presença dos meios mais utilizados pelos departamentos nas comunicações diárias tiveram certa inclinação para os meios informais: conversa, telefonema e reuniões.

\begin{tabular}{lc}
\hline Correio eletrônico & $100,00 \%$ \\
\hline Relatórios & $93,75 \%$ \\
\hline Conversa (corredor) & $93,75 \%$ \\
\hline Telefonema & $87,50 \%$ \\
\hline Reuniões & $81,25 \%$ \\
\hline
\end{tabular}

Tabela I. Meios de comunicação departamentos

Os órgãos de maior capacidade de decisão utilizam correio eletrônico, reuniões com fins de esclarecer e maximizar o entendimento acerca das decisões. No processo de comunicação vertical descendente, todos envolvidos na indús- tria devem tomar ciência das decisões (Pinho, 2006, p.106-112). Nesse sentido, foi solicitado que os respondentes avaliassem tais informações repassadas por essas diretorias.

As diretorias cujas comunicações conseguem atingir as demandas dos setores estudados de forma plena foram Recursos Humanos e Direção Industrial. Seguidas da Direção Administrativa e do órgão máximo de decisão, o Conselho Administrativo.

\begin{tabular}{ll}
\hline Direção de RH & $68,75 \%$ \\
\hline Direção Industrial & $68,75 \%$ \\
\hline Direção administrativa & $43,75 \%$ \\
\hline Conselho administrativo & $43,75 \%$ \\
\hline
\end{tabular}

Tabela II. Avaliação das comunicações das diretorias

Nesse caso, o ponto de partida do processo de comunicação se encontra no nível estratégico do qual descreve Valentim (2010, p. 13-14) em direção aos outros dois níveis, o tático e operacional. Envolve vários espaços internos. Trata de assuntos como situações de risco, prevenção de acidentes, processos de produção, análise de indicadores e análise de laboratórios nas comunicações entre os departamentos e setores da indústria.

Os Departamentos $C Q, R H$ e ST realizam frequente feedback com as diretorias. O CQ tem contato mais efetivo com a Direção Industrial em $75 \%$ das demandas semanais. A proximidade na localização de ambas na planta industrial e sua atribuição voltada à questão da qualidade potencializam essa aproximação. $\mathrm{O} \mathrm{RH}$ tem uma comunicação dinâmica entre com ConseIho de Administração, Direção do Centro de Informação, Direção Jurídica e a Direção de Administração. Para o ST responsável pela segurança de todo o parque fabril e de ampla complexidade e periculosidade, requer constante acompanhamento da Direção Industrial contribuindo assim para um contato permanente e diário. Esse processo de comunicação ascendente permite fortalecer a presença da informação potencializando seu efetivo uso mediado por agentes mediadores ou gatekeepers.

Considerando o complexo arranjo e organização de Setores, Departamentos e Diretorias a pesquisa, além da comunicação entre níveis hierárquicos, visou identificar as comunicações entre Setores e os Departamentos pesquisados numa perspectiva horizontal.

Moagem, Tratamento de Caldo, Destilaria/Secagem Levedura, Fábrica de Açúcar, Re- 
finaria Amorfo e Granulado, Geração de Energia Elétrica, Engenharia Elétrica, Manutenção Elétrica, Moenda 1, 2 e 3, Carregamento, Metrologia são setores de permanente comunicação entre os departamentos analisados. Cabe destacar, que na maioria das avaliações houve oscilações nas respostas. No geral, esta oscilação acabou sendo negativa já que os respondentes avaliaram que as informações comunicadas atenderiam parcialmente em $43,75 \%$ ao contrário de $31,25 \%$ com satisfação plena. Nesse intuito, buscando evidenciar o que possivelmente ocasionou tal avaliação no processo de comunicação entre os setores e departamentos, buscou-se identificar suas causas. Os meios mais utilizados junto aos setores repetem os da tabela 1 acrescidos do mural de avisos e rádio comunicadores. Sirenes e similares, cartazes e faixas foram apresentados como meios frequentemente presentes nas rotinas entre os setores. Todos avaliam como meios significativos. Entretanto, em alguns momentos relatam que o excesso de rádio comunicador provoca interferência na comunicação.

É fundamental identificar a ocorrência de problemas nos meios ou nas práticas que impedem a dinâmica do processo de comunicação na indústria sucroalcooleira. Considerando o contexto que envolve o processo de comunicação nesta pesquisa, o setor sucroalcooleiro, os departamentos elegeram uma os meios de acordo com suas rotinas.

Resguardas as características dos departamentos, diretorias e setores no centro do processo emerge no ambiente interno o agente mediador da informação. Tal agente interfere em momentos de incidentes no auxílio da busca por informações. Os meios ou recursos mais usuais nas buscas pelos respondentes foram Internet e correio eletrônico $93,75 \%$. Intranet e base de dados com $68,75 \%$ e $56,25 \%$ respectivamente. Rádio comunicador por $37,50 \%$ e visita em campo, setor de informação da indústria, relatórios citados por $31,25 \%$. Cabe destacar que o setor de informação está diretamente vinculado a Direção de Informação que fornece suporte a toda a indústria em tecnologia de comunicação da informação.

Apesar de relatar confiança com as informações encontradas no ambiente virtual, ao avaliar tais meios é tecida uma crítica acentuada sobre a internet e sobre o setor de informação da indústria durante as entrevistas. A restrição de acesso de conteúdos, baixo desempenho e ausência de equipamentos como motivações as avaliações. A internet possui bloqueios de acesso a conteúdos, o que impossibilita, por exemplo, para um dos respondentes a pesquisa sobre a elaboração de treinamentos ou computadores com controle de acesso a mídias.

Destacam-se dois aspectos nessa avaliação. Por um lado, as organizações devem preocupar-se com possíveis gargalos ou defeitos em equipamentos e ruídos nos meios utilizados que atrapalhem a dinâmica da mediação das informações no processo de comunicação. Para Souza (1991, p.34), "[...] de qualquer ângulo que se considere, é impossível qualquer atividade industrial sem uso da informação". A outra questão diz respeito ao ambiente competitivo. $O$ segmento industrial o qual a indústria faz parte, como dito anteriormente, é alvo de interesse internacional. Portanto, exigindo acentuado controle sobre informações ligadas aos processos internos de toda ordem.

Considerando uma lista de potenciais agentes mediadores da informação presentes nas atividades para auxiliar os respondentes ou os envolvidos no processo de comunicação, foi solicitada a indicação dos mais frequentes. Colega de equipe/colaboradores (setor, departamentos...) e Superiores hierárquicos (diretor, supervisor, etc.) com $87,50 \%$ e $68,75 \%$ respectivamente mais citados e avaliados como plenamente confiáveis.

As instituições de ensino superior e institutos de pesquisa nacional e internacional não são consultados por $81,25 \%$ das indicações enquanto agentes mediadores da informação.

\begin{tabular}{lrc}
\hline Agentes & Atende & Confiam \\
\hline Diretor & $62,50 \%$ & $81,25 \%$ \\
\hline Gerente & $68,75 \%$ & $75,00 \%$ \\
\hline Coordenador & $62,50 \%$ & $62,50 \%$ \\
\hline Supervisor & $50,00 \%$ & $56,25 \%$ \\
\hline
\end{tabular}

Tabela III. Agentes mediadores

A confiança nos agentes da Tabela III está diretamente vinculada aos atributos encontrados nesses agentes como experiência na indústria, informação atualizada, influência e qualidade da informação. Os agentes mediadores ou gatekeepers são ágeis e transparentes quanto às informações disponibilizadas vinculadas aos espaços em que atua. Nesse entendimento, agentes mediadores da informação agem nos espaços em que circulam a informação, potencializando-os em sua atuação. Nota-se que, aqui consideramos como agente tanto um profissional com ou sem formação universitária. Os meios que esses agentes costumam disponibilizar informações estão concentrados nas con- 
versas, correio eletrônico (via e-mail), telefonemas e relatórios para $93,75 \%$ das respostas. Além disso, a disponibilização por normas regulamentadoras e visitas técnicas com $50 \%$.

\section{Considerações finais}

Este relato de pesquisa teve como objetivo apresentar os principais resultados da pesquisa com foco em analisar os processos de comunicação e mediação da informação em uma indústria de alta produtividade do setor sucoalcooleiro do Estado de São Paulo. Foi possível constatar a ampla interação e direções no processo de comunicação dos Departamentos de CQ, RH e ST entre os demais departamentos, diretorias e setores. Os meios utilizados nesse processo são considerados relevantes ao feedback mesmo com algumas ressalvas.

A mediação da informação realizada pelos agentes mediadores ocorre como compreendida e ancorada na ação de interferência em aproximar a informação para resolução de problemas. Ainda mais, possibilitou identificar os agentes mediadores ou gatekeepers no contexto abordado próximos da realidade da industria em posição central entre pólos enquanto parte do processo de comunicação. Os deparamentos creditam aos agentes a condição de especialistas, seja pela experiência, dominio técnico ou caraterísitca de liderança.

As barreiras que incidem como ruídos, defeitos, excesso de meios como o rádio comunicador, baixo desempenho da internet ou restrição de conteúdos são indícios de ações de análise. Contudo, não houve intenção de esgotamento do tema, pelo contrário, revela necessidade de operacionalizar aspectos teóricos e práticos da área quanto à compreensão de processos complexos que envolve a informação. Portanto, outras variáveis são passíveis de reflexões, além da aproximação dos estudos da Ciência da Informação neste cluster no Brasil.

\section{Agradecimentos}

A pesquisa foi financiada na primeira fase pelo Conselho Nacional de Desenvolvimento Científico e Tecnológico (CNPq) e na fase final pela Fundação de Amparo à Pesquisa do Estado de São Paulo (FAPESP).

\section{Referências}

Ackoff, Russell L. (1957). Planejamento de pesquisa social. São Paulo: Herder; Editora USP, 1967. 113-177.

Adorno, Theodor W. (1977). A indústria cultural. // Cohn, Gabriel (Org.). Comunicação e indústria cultural: leituras de análise dos meios de comunicação na sociedade contemporânea e das manifestações da opinião pública, propaganda e cultura de massa nessa sociedade. 5. ed. São Paulo: Ed. Nacional, 1977. 287-295.
Alaszewski, Andy (2006). Using diaries for Social Reseach. London: Sage publications, 2006.

Almeida Júnior, Oswaldo Francisco de (2009). Mediação da Informação e Múltiplas Linguagens. // Tendências na Pesquisa Brasileira em Ciência da Informação. 2:1 (janeiro-dezembro 2009) 89-103.

Andrade, Manuel Correia de Oliveira (1994). Modernização e pobreza: a expansão da agroindústria canavieira e seu impacto ecológico e social. São Paulo: EDUNESP, 1994.

Bortolin, Sueli (2010). Mediação oral da literatura: a voz dos bibliotecários lendo ou narrando. Tese (Doutorado em Ciência da Informação). Marília: Universidade Estadual Paulista, 2010.

Bray, Sílvio Carlos; Ferreira, Enéas Rente; Ruas, Davia Guilherme Gaspar (2000). As políticas da agroindústria canavieira e o Proálcool no Brasil. Marília: Unesp Marília Publicações, 2000

Bruyne, Paul de; Herman, Jacques; Schoutheete, Marc de (1977). Dinâmica da Pesquisa em Ciências Sociais: os pólos da prática metodológica. Rio de Janeiro: F. Alves, 1977. 216-227.

CNI - Confederação Nacional da Indústria (2012). Bioetanol: o futuro renovável. Brasília, DF: CNI, 2012.

Cherry, Colin (1968). A comunicação humana: uma recapitulação, uma vista de conjunto e crítica. São Paulo: Cultrix; Editora da Universidade de São Paulo, 1968.

Cretella Júnior, José; Cintra, Geraldo Ulhôa (1956). Dicionário Latino-Português. 7. ed. São Paulo: Companhia Editora Nacional, 1956.

Cunha, Murilo Bastos; Cavalcanti, Cordélia R. de Oliveira (2008). Dicionário de Biblioteconomia e Arquivologia. Brasília, DF: Briquet de Lemos, 2008.

Cunha, Antônio Geraldo da (2007). Dicionário etimológico de língua portuguesa. 3. ed. Rio de Janeiro: Lexicon, 2007.

Davallon, Jean (2007). A mediação: a comunicação como processo? // Prisma. 11 (junho 2007).

Diaz Bordenave, Juan E. (1985). O que é Comunicação. 7. ed. São Paulo: Brasiliense, 1985.

Escosteguy, Ana Carolina (2001). Os estudos culturais. /I Hohlfeldt, Antônio; Martino, Luiz C.; França, Vera Veiga (Org.). Teorias da Comunicação: conceitos, escolas e tendências. Petrópolis: Vozes, 2001. 151-170.

Fernando, Manuel Garcia (2010). La Encuesta. // Fernando, Manuel Garcia; Ibáñez, Jesús; Alvira, Francisco. El análisis de la realidad social: Métodos y técnicas de investigación. 3. ed. Madrid: Alianza Editorial, 2010. 100-201.

Freitag, Barbara (1994). A teoria crítica: ontem e hoje. 5. ed. São Paulo: Brasiliense, 1994.

Furstenau, Eugênio (1976). Dicionário de termos técnicos. 5. ed. Porto Alegre: Globo, 1976.

Furtado, Celso (2005). Formação econômica do Brasil. 32. ed. São Paulo: Companhia Editora Nacional, 2005.

Galeano, Eduardo (2001). As veias abertas da América Latina. 40. ed. Rio de Janeiro: Paz e Terra, 2001.

Gil, Antonio Carlos (2009). Métodos e técnicas de pesquisa social. 6. ed. São Paulo: Atlas, 2009.

Halliday, Tereza Lúcia (1975). Comunicação em Organizações no Processo de Desenvolvimento: a função informativa dos técnicos. Petrópolis: Vozes, 1975.

Lefèvre, Fernando; Lefèvre, Ana Maria (2005). Depoimentos e discursos: uma proposta de análise em pesquisa social. Brasília: Liber Livro, 2005.

Matellart, Armand; Matellart, Michèle (2011). Histórias das teorias da comunicação. 14. ed. São Paulo: Loyola, 2011.

Martin-Barbero, Jesús (2009). Dos meios às mediações: comunicação, cultura e hegemonia. 6. ed. Rio de Janeiro: Editora UFRJ, 2009. 
Mont'alegre, Omer (1974). Acúcar e capital. Rio de Janeiro: Instituto do Açúcar e do Álcool, 1974.

Peirce, Charles Sanders (1972). Semiótica e filosofia. São Paulo: Cultrix, 1972.

Petrone, Maria Teresa Schorer (1968). A lavoura canavieira em São Paulo: expansão e declínio (1765-1851). São Paulo: Difusão Européia do Livro, 1968.

Pina, Hélio (1972). A agroindústria açucareira e sua legislação. São Paulo: Apec, 1972.

Pinho, José Benedito (2006). Comunicação nas organizações. Viçosa: Editora UFV, 2006.

Rabaça, Carlos Alberto; Barbosa, Gustavo Guimarães (2001). Dicionário de Comunicação. 2.ed. Rio de Janeiro: Campus, 2001.

Rea, Louis M.; Parker, Richard A. (2000). Metodologia de Pesquisa: do planejamento à execução. São Paulo: Pioneira, 2000. 123-151.

Safatle Netto, Fernando (2011). A economia política do etanol: a democratização da agroenergia e o impacto na mudança do modelo econômico. São Paulo: Alameda, 2011.

Sanz-Casado, Elias (1994). Manual de estudios de usuarios Madrid: Pirámide, 1994.

Selltiz, Claire et.al. (1971). Métodos de Pesquisa nas Relações Sociais São Paulo: Herder; Editora da Universidade de São Paulo, 1971
Schleyer, Judith Rebeca (1982). Estudos de usuários: introdução à problemática e à metodologia. // Estudos avançados em Biblioteconomia e Ciência da Informação. 1 (1982) 49-71.

Sousa, José Martinez de. (2004). Diccionario de bibliología y ciencias afines. 3.ed. Gijón: Trea, 2004.

Souza, Franciso das Chagas de (1991). Uso da Informação na indústria como paradigma para o desenvolvimento econômico // Ciência da Informação. 20:1 (1991) 34-36.

Santaella, Lúcia; Noth, Winfried (2004). Comunicação e semiótica. São Paulo: Hacke Editores, 2004.

Torrinha, Francisco (1939). Dicionário Português-Latino. 7. ed. Porto: Editorial Domingo Barreira, 1939.

Valentim, Marta Lígia Pomim (Org.) (2010). Ambientes e Fluxos de informação. São Paulo: Cultura Acadêmica, 2010.

Wolf, Mauro (2006). Teorias da comunicação. 8. ed. São Paulo: Editorial presença, 2006.

Yin, Robert K. (2010). Estudo de Caso: palejamento e métodos. 4. ed. Porto Alegre: Bookman, 2010. 19-45.

Enviado: 2014-03-31. Segunda versión: 2014-06-09 Aceptado: 2014-06-23 